\title{
A predictive genetic signature for response to fluoropyrimidine-based neoadjuvant chemoradiation in clinical Stage II and III rectal cancer
}

\section{Jason Chan ${ }^{1}$, Michael T. Kinsella ${ }^{2}$, Joseph E. Willis ${ }^{3}$, Huankai Hu ${ }^{3}$, Harry Reynolds $\mathrm{Jr}^{4}$, Conor Delaney ${ }^{4}$, Andrea McCulla ${ }^{5}$, Steve Deharo ${ }^{5}$, Miika Ahdesmäki ${ }^{5}$, Wendy Louise Allen ${ }^{6}$, Patrick G. Johnston ${ }^{6}$ and Timothy J. Kinsella ${ }^{1}$ *}

${ }^{1}$ Department of Radiation Oncology, Brown University, Providence, RI, USA

${ }^{2}$ Department of Radiation Oncology, Memorial Sloan Kettering Cancer Center, New York, NY, USA

${ }^{3}$ Department of Pathology, Case Medical Center, Cleveland, OH, USA

${ }^{4}$ Department of Surgery, Case Medical Center, Cleveland, OH, USA

${ }^{5}$ Almac Diagnostics, Craigavon, UK

${ }^{6}$ Centre for Cancer Research and Cell Biology, Queen's University Belfast, Belfast, UK

\section{Edited by:}

Kwan-Hwa Chi, Shin-Kong Memorial Hospital, Taiwan

Reviewed by:

Daniel Grant Petereit, Rapid City

Regional Hospital, USA

Skye Hung-Chun Cheng, Koo

Foundation Sun Yat-Sen Cancer

Center, Taiwan

\section{${ }^{*}$ Correspondence:}

Timothy J. Kinsella, Department of Radiation Oncology, Rhode Island Hospital, Physician's Office Building, Suite 130, 110 Lockwood Street,

Providence, RI 02903, USA

e-mail: tkinsella@lifespan.org
Purpose: Pre-operative chemoradiation (CRT) is currently the standard of care for patients with clinical stage II and III rectal cancer but only about $45 \%$ of patients achieve tumor downstaging and $<20 \%$ of patients achieve a pathologic complete response. Better methods to stratify patients according to potential neoadjuvant treatment response are needed. We used microarray analysis to identify a genetic signature that correlates with a pathological complete response (pCR) to neoadjuvant CRT. We performed a gene network analysis to identify potential signaling pathways involved in determining response to neoadjuvant treatment.

Patients and Methods: We identified 31 T3-4 N0-1 rectal cancer patients who were treated with neoadjuvant fluorouracil-based CRT. Eight patients were identified to have achieved a pCR to treatment while 23 patients did not. mRNA expression was analyzed using cDNA microarrays. The correlation between mRNA expression and pCR from pretreatment tumor biopsies was determined. Gene network analysis was performed for the genes represented by the predictive signature.

Results: A genetic signature represented by expression levels of the three genes EHBP1, STAT1, and GAPDH was found to correlate with a pCR to neoadjuvant treatment. The difference in expression levels between patients who achieved a pCR and those who did not was greatest for EHBP1. Gene network analysis showed that the three genes can be connected by the gene ubiquitin $\mathrm{C}$ (UBC).

Conclusion: This study identifies a 3-gene signature expressed in pre-treatment tumor biopsies that correlates with a pCR to neoadjuvant CRT in patients with clinical stage II and III rectal cancer. These three genes can be connected by the gene UBC, suggesting that ubiquitination is a molecular mechanism involved in determining response to treatment. Validating this genetic signature in a larger number of patients is proposed.

Keywords: rectal neoplasms, ubiquitination, gene array, UBC, EHBP1

\section{INTRODUCTION}

\section{TREATMENT OF LOCALLY ADVANCED RECTAL CANCER}

An estimated 40,340 new cases of rectal cancer will be diagnosed in 2013 (1). Rectal cancer is a highly treatable and often curable disease when localized. Surgery is the mainstay of treatment. The 2-year local recurrence rates after surgery alone for Stage II and III rectal cancers are $<10 \%(2,3)$. The 5 -year survival rates after surgery alone for T3 and T4 rectal cancers vary from 44 to $60 \%$ and from 25 to $30 \%$ in patients with lymph node involvement (4).

The addition of postoperative radiation improves localregional control whilst the use of postoperative chemotherapy is associated with a survival benefit (5). When combined, the use of postoperative radiation together with a fluorouracilbased radiosensitizer significantly improves the results of therapy for rectal carcinoma with a poor prognosis, as compared with postoperative radiation alone (6).

The advent of pre-operative chemoradiation (CRT) represents a new phase in improving rectal cancer treatment allowing for tumor downstaging prior to radical resection. This has been associated with considerable advantages over postoperative approaches (7) including improvement of local disease control $(4,8-14)$, overall and cancer specific-survival (15), and allowing for sparing of 
the rectal sphincter in some patients where an abdomino-perineal resection would have been necessary $(16,17)$. Another important advantage of pre-operative CRT is allowing for pathological assessment of the resected specimen after neoadjuvant treatment, which has been shown to be predictive of treatment outcomes (18-21).

\section{PREDICTING RESPONSE TO NEOADJUVANT CHEMORADIATION}

Despite these advantages, the clinical and pathological response to pre-operative CRT is extremely variable between individual patients. Only about $45 \%$ of treated patients achieve $\mathrm{T}$ stage downstaging $(16,22-24)$, and $<20 \%$ of treated patients achieve a pathological complete response (pCR), where no viable tumor cells are found in the resected specimen after neoadjuvant treatment $(23,25,26)$. Several predictive clinical factors have been identified including tumor stage, tumor mobility, proportion of rectal circumference involved by tumor, and tumor differentiation (9). Radiation dose and time elapsed from radiation to surgery are also important $(4,13,27)$.

Furthermore, such variable individual responses to neoadjuvant treatment raise the question of genetic and epigenetic heterogeneity of rectal tumors and motivate the need to discover predictive biological markers to stratify patients according to potential treatment response. This would ultimately have the benefit of modifying treatment so that, for example, patients with little likelihood of having a therapeutic benefit from pre-operative CRT would be spared the potential morbidity (28). Conversely, patients predicted to have a pCR might be spared the morbidity associated with surgery (29-31).

A recent review of predictive biomarkers for response to neoadjuvant CRT identified six biomarkers with more than five studies in the literature: p53, epidermal growth factor receptor (EGFR), Ki-67, p21, bcl-2/bax, and thymidylate synthase (TS) $(32,33)$. The predictive value of these biomarkers is mostly derived from immunocytochemistry analyses of pre-operative biopsy material. p53 is the most studied biomarker but conflicting data exists regarding the predictive value of $\mathrm{p} 53$ expression and $\mathrm{p} 53$ mutations $(8,9,34,35)$. Among these single gene biomarkers, TS currently appears to be the most promising avenue of investigation in predicting response to CRT. TS is the primary target for 5-FU activity and its increased expression has been identified as a poor prognostic and predictive factor in various cancers (36-41). A recent prospective study stratified 37 out of 135 rectal cancer patients into a poor risk group based on genotypes that correlate with increased TS expression and activity (42). However, the data are not consistent throughout the literature as regards the significance of TS expression level as a predictor of response to FU-CRT (32). This is in part due to small study populations and differences in treatment regimens but much of the discrepancy in the literature probably derives from the complex nature of these pathways, which single gene expression assays cannot adequately explain.

One of the most useful recent advances in the ability to investigate biological systems is the advent of cDNA array technology. DNA microarrays contain oligonucleotide or cDNA probes for measuring the expression of thousands of genes in a single hybridization experiment and allow for the potential to discover predictive genetic "signatures" that are represented by numerous genes products (43-46). A recent study discovered a genetic signature of 13 miRNAs that correlated with pCR after neoadjuvant CRT in locally advanced rectal cancer patients (47).

Using cDNA microarrays in this manner, we attempt to identify gene clusters associated with pCR after neoadjuvant CRT in a small group of rectal cancer patients. We obtained formalin-fixed paraffin-embedded specimens taken from pre-treatment biopsies of previously treated patients and identified 8 patients who achieved pCR and 23 patients who did not achieve pCR. We found a genetic signature that was found to be correlated with $\mathrm{pCR}$ and was independent of clinical factors. This genetic signature consisted of three genes EHBP1, STAT1, and GAPDH. Network analysis revealed that all three genes can be connected through a single gene Ubiquitin C (UBC), suggesting that ubiquitination may be a molecular mechanism involved in determining response to FU-CRT.

\section{MATERIALS AND METHODS PATIENTS AND TISSUE SPECIMENS}

Forty patients treated at the University Hospitals Case Medical Center with clinical Stage II and III rectal cancer who underwent pre-treatment biopsies and post-treatment pathological assessment of tumor response to neoadjuvant CRT were included in this study. The retrospective inclusion criteria were locally advanced T3/T4 N0-1 M0 rectal cancer by endoscopic ultrasound (EUS) in patients who were not previously treated. The exclusion criteria included recurrent colorectal cancer or the presence of a known coagulopathy. Biopsies were taken at the time of initial diagnosis. Patients then received standard CRT. Finally, patients underwent total mesorectal excision. Multiple sections of preoperative cancer biopsies (average 10 per case) were subjected to laser capture microdissection using an Arcturus Veritas Laser Capture Microdissection Microscope (Applied Biosystems).

\section{CHEMORADIATION THERAPY}

Patients received 54-63 Gy at 1.8 Gy daily fractions over 6-7 weeks depending on tumor volume determined by CT and EUS. CTbased 3-D conformal radiation therapy treatment planning was used. 5-FU was administered as a continuous infusion throughout radiation therapy. A dose of $200-250 \mathrm{mg} / \mathrm{m}^{2} /$ day was administered typically through a surgically placed port.

\section{PATHOLOGY}

Post-chemoradiation therapy resection specimens were processed. The resected specimens were fixed in formaldehyde and a minimum of four paraffin blocks were processed for each sample. The tumor response in the surgical resection specimen was graded according to previously published criteria (48). Tumor regression of the primary tumor was measured by laser capture microscopy to compare the amount of tumor versus stromal tissues. Tumor regression scores were assigned as follows: grade 0 , no residual tumor; grade 1, rare residual tumor cells; grade 2, fibrosis with residual cancer; and grade 3 , dominant residual cancer. pCR was defined by a tumor regression score of 0 . Non-pCR was defined by tumor regression scores of 2 and 3 . One patient did not receive neoadjuvant radiation therapy and was excluded from analysis. Seven specimens were assigned a tumor regression score of 1 and were excluded from analysis. 


\section{GENETIC ANALYSIS}

mRNA extracted from viable tumor cells derived from formalinfixed paraffin-embedded tissue were amplified and converted to cDNA using the NuGEN WT-Ovation FFPE RNA amplification V2

Table 1 | Patient characteristics

\begin{tabular}{|c|c|c|c|c|}
\hline Patient ID & Sex & $\begin{array}{l}\text { Patient } \\
\text { status }\end{array}$ & $\begin{array}{l}\text { Follow up } \\
\text { (months) }\end{array}$ & $\begin{array}{l}\text { Tumor regression } \\
\text { regression score }\end{array}$ \\
\hline S0740F0024 & $\mathrm{F}$ & ANED & 126 & 0 \\
\hline S0740F0027 & $\mathrm{F}$ & ANED & 38 & 0 \\
\hline S0740F0028 & $M$ & ANED & 13 & 0 \\
\hline S0740F0032 & M & DNED & 55 & 0 \\
\hline S0740F0034 & $\mathrm{F}$ & ANED & 56 & 0 \\
\hline S0740F0040 & $M$ & AWD & 5 & 0 \\
\hline S0740F0001 & $M$ & ANED & 52 & 0 \\
\hline S0740F0002 & $M$ & ANED & 27 & 0 \\
\hline S0740F0017 & $M$ & AWD & 6 & 2 \\
\hline S0740F0020 & $M$ & AWD & 24 & 2 \\
\hline S0740F0030 & $M$ & ANED & 15 & 2 \\
\hline S0740F0036 & $M$ & AWD & 99 & 2 \\
\hline S0740F0038 & $\mathrm{F}$ & DWD & 14 & 2 \\
\hline S0740F0025 & $M$ & ANED & 48 & 3 \\
\hline S0740F0026 & $\mathrm{F}$ & ANED & 53 & 3 \\
\hline S0740F0029 & $M$ & AUNK & 14 & 3 \\
\hline S0740F0031 & $M$ & AWD & 21 & 3 \\
\hline S0740F0033 & $\mathrm{F}$ & AWD & 14 & 3 \\
\hline S0740F0035 & $M$ & AUNK & 3.5 & 3 \\
\hline S0740F0037 & $M$ & ANED & 14.5 & 3 \\
\hline S0740F0039 & $M$ & AUNK & 29 & 3 \\
\hline S0740F0004 & $M$ & AUNK & 17 & 3 \\
\hline S0740F0005 & $M$ & AWD & 54 & 3 \\
\hline S0740F0006 & $M$ & ANED & 48 & 3 \\
\hline S0740F0007 & $M$ & ANED & 30 & 3 \\
\hline S0740F0008 & $M$ & ANED & 46 & 3 \\
\hline S0740F0009 & $M$ & AWD & 27 & 3 \\
\hline S0740F0010 & $M$ & ANED & 47 & 3 \\
\hline S0740F0011 & $\mathrm{F}$ & AWD & 7 & 3 \\
\hline S0740F0012 & $\mathrm{F}$ & ANED & 48 & 3 \\
\hline S0740F0016 & $\mathrm{M}$ & ANED & 48 & 3 \\
\hline
\end{tabular}

Patient status: ANED, alive, no evidence of disease; AWD, alive with disease; $D W D$, dead with disease; DNED, dead, no evidence of disease; $A U N K$, alive disease unknown. Tumor regression score: $0=$ no residual tumor; $2=$ fibrosis with residual cancer; $3=$ dominant residual cancer, no regression. kit (NuGEN Technologies, Inc.). The cDNA was fragmented and labeled using the NuGEN Encore kit and hybridized to the Almac Diagnostics Colorectal Cancer DSA ${ }^{\circledR}$ arrays. Each microarray contains cDNA probes for measuring the expression of thousands of genes in a single hybridization experiment. One tumor specimen was identified as an outlier following data quality and integrity assessment and was excluded from the analysis.

\section{STATISTICAL METHODS}

Following percent present filtering and 50\% variance intensity filtering, signature generation starting from 8496 probe sets was conducted. Genetic signatures consisted of predictive probe set signatures of different sizes that were evaluated under cross validation and utilizing forward feature selection for the selection of the optimal signature, following the best practices of the MicroArray Quality Control consortium (49). The performance of each genetic signature was evaluated in two ways: the area under the Receiver Operating Characteristic (ROC) curve (AUC) for response detection and the signature's independence from clinical covariates. After the highest performing genetic signature was identified, we performed a permutation test by randomly shuffling the response information for the samples. Finally, functional and topological analyses were performed to identify biological entities associated with the gene list represented by our genetic signature using Ingenuity Pathway Analysis ${ }^{\circledR}$ (IPA).

\section{RESULTS}

\section{PATIENT CHARACTERISTICS}

Two sample groups were identified from a sub-population of 31 rectal cancer patients with varying response to 5 -FU and radiotherapy (Table 1). Eight responders were defined as having a tumor regression score of 0 and 23 non-responders defined having a

Table 3 | List of clinical covariates used in testing for independence of genetic signature prediction.

Clinical covariates

1. Follow up length

2. Date of last follow up

3. Gender

4. Patient status

5. Tumor regression score

6. Response

7. Ethnicity

Table 2 | List of genes that is represented by the genetic signature.

\begin{tabular}{llll}
\hline ProbeSet ID & Gene symbol & Gene title & Entrez gene \\
\hline ADXCRAD_CX760189_at & EHBP1 & EH domain binding protein 1 & 23301 \\
ADXCRAG_AL831944_at & Antisense & Antisense & Antisense \\
AFFX-HUMISGF3A/M97935_MA_at & STAT1 & signal transducer and activator of transcription 1,91 kDa \\
AFFX-HUMGAPDH/M33197_5_at & GAPDH & Glyceraldehyde-3-phosphate dehydrogenase & 6772
\end{tabular}

The AdXCRAG_AL831944 probe set is an antisense transcript and does not represent gene function. The genetic signature, therefore, represents the three genes: EHBP1, STAT1, and GAPDH. 

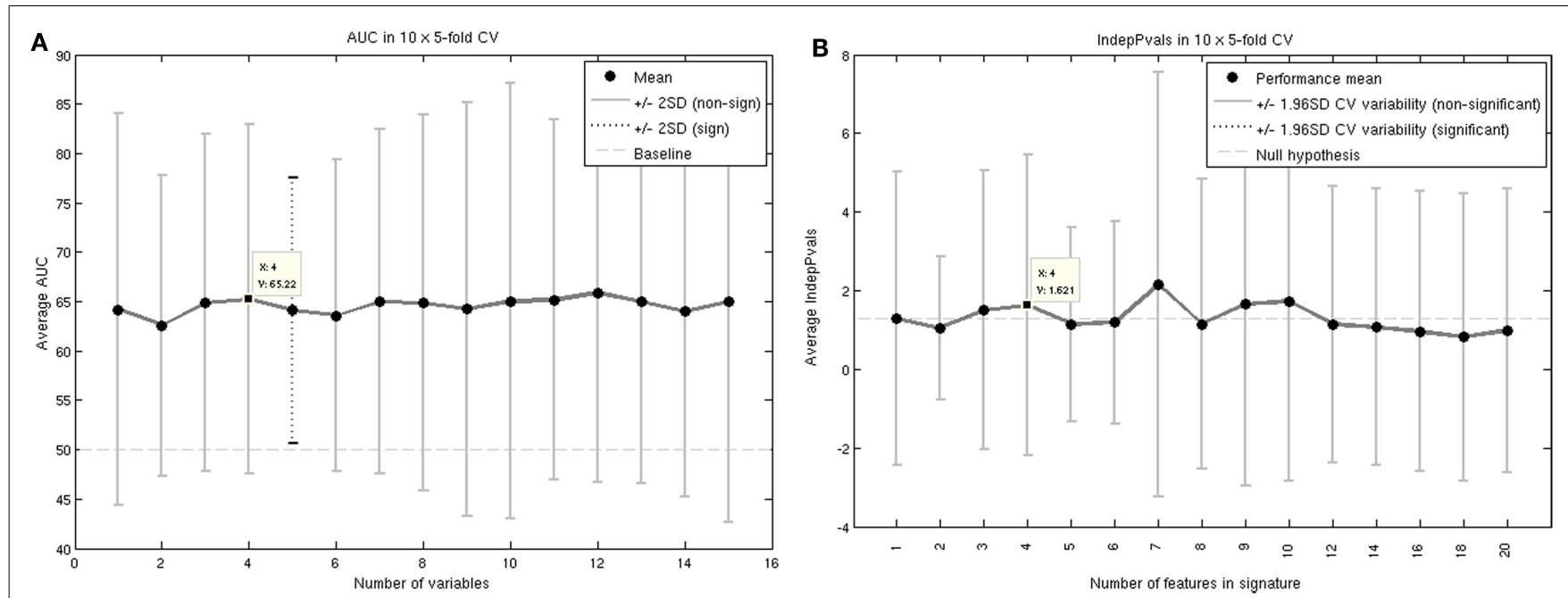

FIGURE 1 |AUC (A) and independence to clinical covariates p-values (B) for the highest performing genetic signature

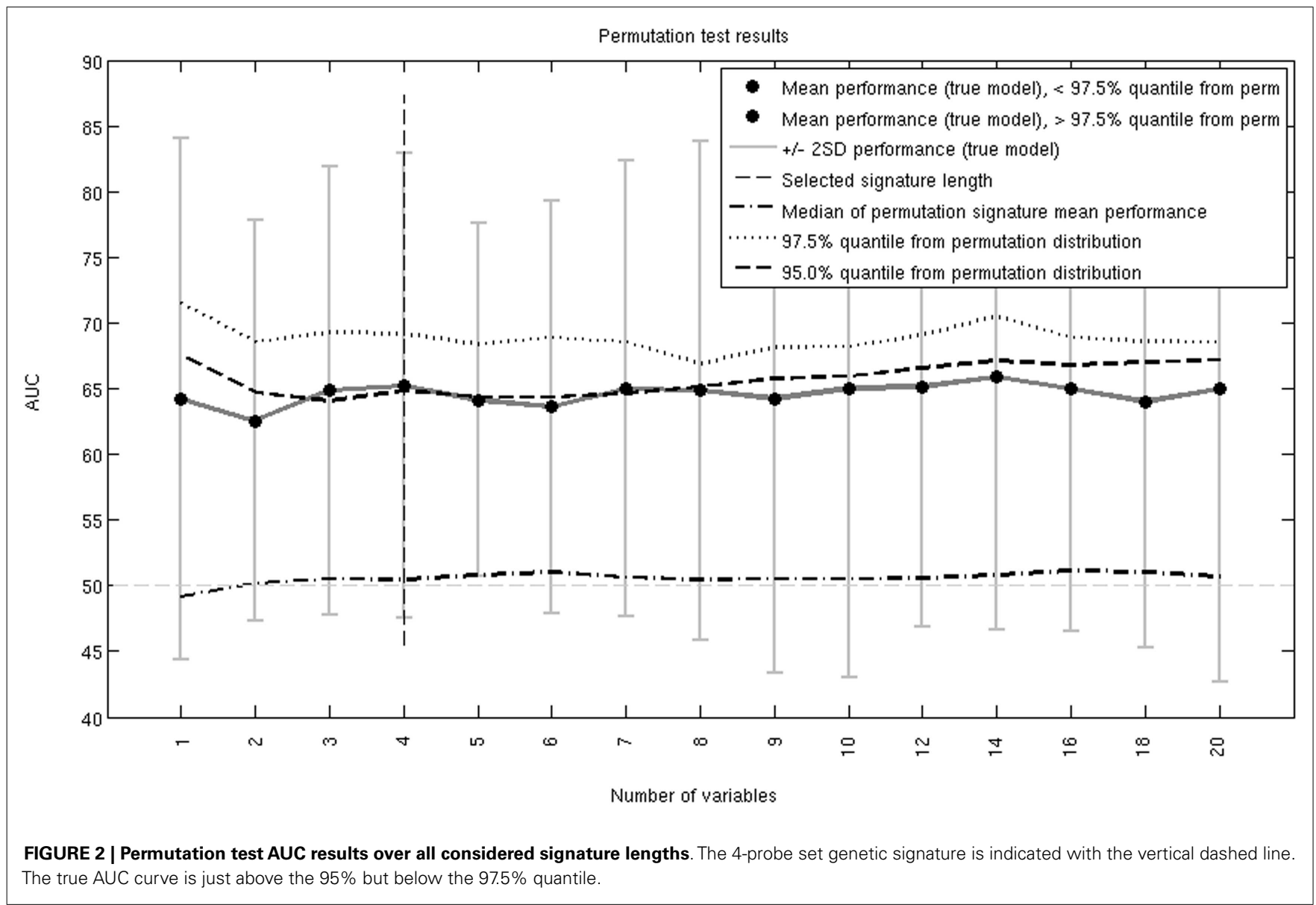

tumor regression score of 2 or 3 . At the time of analysis, 16 patients were alive without evidence of disease, 9 were alive with evidence of disease, 4 were alive with unknown disease status, 1 died with evidence of disease, and 1 died with no evidence of disease.

\section{GENETIC SIGNATURE GENERATION}

Gene expression signatures were generated in rectal cancer patients treated with neoadjuvant CRT. A 4-probe set signature was discovered to be the highest performing genetic signature (Table 2). 


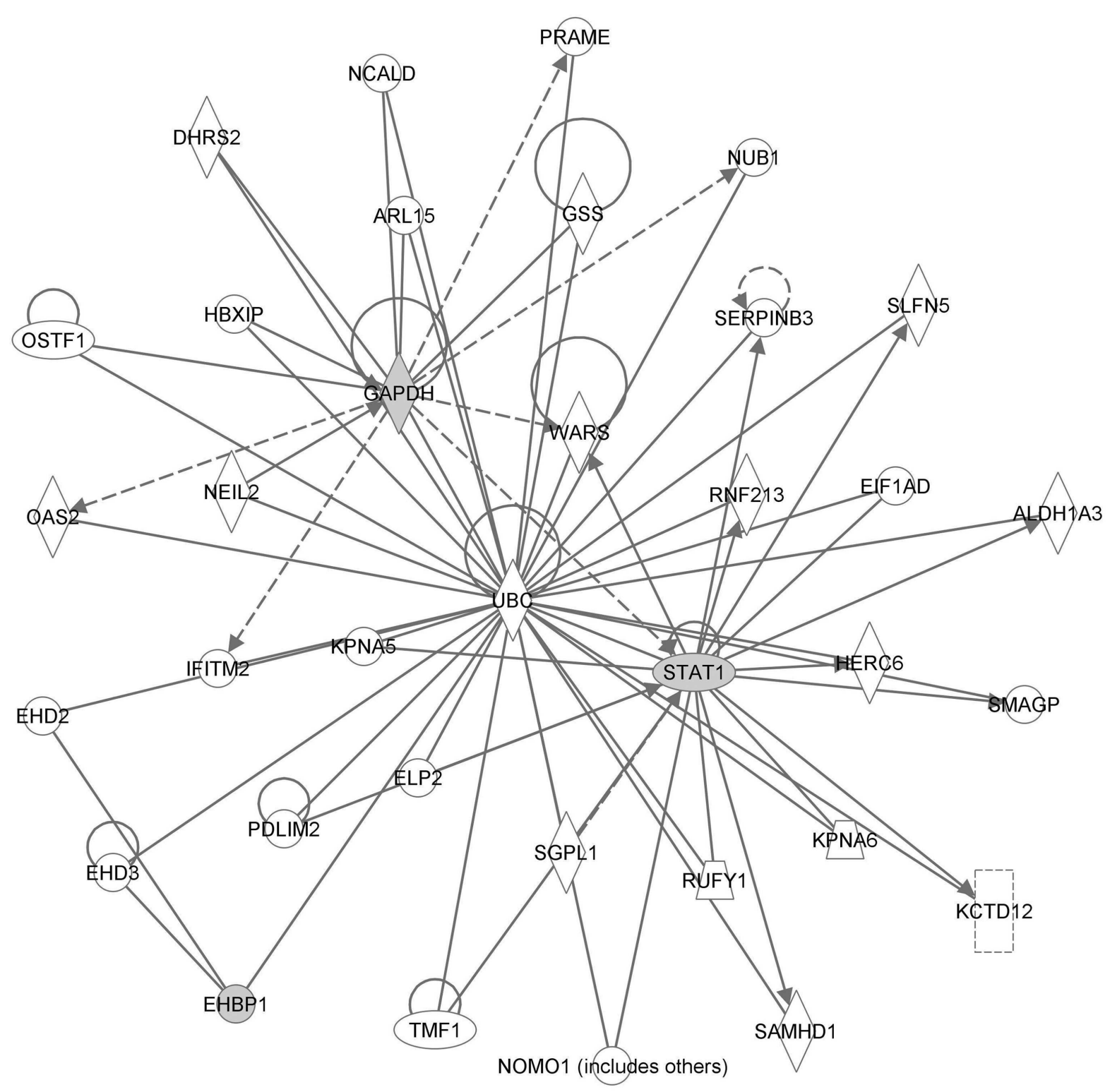

FIGURE 3 | Network analysis results. Genes present in the genetic signature are colored gray.

Each probe set consists of genetic probes with a single genetic target. One probe set targets an antisense transcript and therefore does not provide information about gene function. The other three genes represented by this genetic signature include EHBP1, STAT1, and GAPDH.

Repeated testing of patient samples showed that the average area under ROC curves (AUC) was 65\%. To test whether this genetic signature was an independent predictive factor, we identified a list of clinical factors to rule out intercorrelations (Table 3). The clinical covariate independence $p$-values were on average below 0.05 or above 1.3 on the log scale (Figure 1).

This signature was further studied in a permutation analysis. A null hypothesis AUC distribution was produced by randomly shuffling the patient response information. The median, 95, and 97.5\% quantiles are shown in Figure 2. The 4-probe set genetic signature on average generates an AUC above the $95 \%$ quantile but below the $97.5 \%$ quantile. Therefore, the selected signature does not pass permutation testing at the stringent $97.5 \%$ quantile or $p$-value of 0.05 threshold, but this may, in part, be due to the small sample size.

\section{FUNCTIONAL ANALYSIS OF THE GENETIC SIGNATURE}

Network analysis revealed that all three genes represented by the genetic signature can be connected through a single gene UBC (Figure 3). Furthermore, the probe set for EHBP1 was identified as the strongest differentiator between the responders and non-responders. 


\section{DISCUSSION}

This study identifies a genetic signature that is predictive of pathologic complete response (pCR) to neoadjuvant CRT and found to be independent from clinical factors. The genetic signature was represented by the three genes: EHBP1, STAT1, and GAPDH. EHBP1 expression level was found to be the greatest differentiator between patients that achieved pCR and patients that did not. Functional analysis revealed good connectivity between the genes as they can all be connected through the gene UBC.

\section{pCR PREDICTS TREATMENT OUTCOMES}

The correlation between this novel genetic signature and PCR is significant because $\mathrm{PCR}$ is a predictor of treatment outcomes. Local control rates are improved in patients who achieve $\mathrm{PCR}$ (23). Additionally, the 5-year disease-free survival is about $83 \%$ for patients that achieve pCR and about $66 \%$ for those that do not $(19,48)$. Validating this genetic signature in a larger study population will be needed to assess whether this genetic signature is predictive of treatment outcomes in addition to $\mathrm{PCR}$.

\section{EHBP1, STAT1, GAPDH, AND UBIOUITINATION}

EHBP1 is a gene that is thought to be involved with endocytic trafficking by mediating actin reorganization (50). An intron of EHBP1 is known to bear two SNPs that are associated with prostate cancer (51), but otherwise this gene has not previously been linked with cancer. Whether these SNPs affect gene expression or other downstream signaling effects are also currently unknown.

STAT1 is transcription factor complex that is involved in proapoptotic and anti-proliferative signaling pathways (52), and has been implicated in numerous cancers including colorectal cancer (53). Specific ligand-receptor tyrosine kinase binding induces tyrosine phosphorylation by JAK1 and JAK2, which recruit STAT1 molecules to form STAT1 dimers. STAT1 dimers translocate to the nucleus and function as part of a transcription factor complex. Increased expression of STAT1 has been reported to be a favorable prognostic factor in colorectal cancer $(54,55)$.

GAPDH catalyzes the sixth step in glycolysis and has been implicated in promoting apoptosis (56). GAPDH has been reported to be overexpressed in colorectal cancer (57), but has not been studied as a prognostic or predictive factor.

Ubiquitin $\mathrm{C}$ is a small regulatory protein that labels proteins to be transported and destroyed in proteasomes (58), and its role in colorectal carcinogenesis and colorectal cancer prognosis was recently reviewed (59). In most sporadic colorectal cancers, mutations in APC prevent the ubiquitination of $\beta$-catenin, which is a transcription factor involved in cell proliferation. The downstream effects are that $\beta$-catenin is not recognized by the proteasome and excess $\beta$-catenin will translocate into the nucleus.

\section{CONCLUSION}

This study identifies a 3-gene signature that correlates with a $\mathrm{PCR}$ to neoadjuvant CRT in patients with clinical stage II and III rectal cancer. These three genes can be connected by the gene UBC, suggesting that ubiquitination is a molecular mechanism involved in determining response to neoadjuvant CRT.

\section{ACKNOWLEDGMENTS}

This project is funded by NIH grants U56 CA112963 and P50 CA150964; the Pratt Radiation Oncology Research Fund; and the David and Barbara Jacobs Foundation.

\section{REFERENCES}

1. Siegel R, Naishadham D, Jemal A. Cancer statistics, 2013. CA Cancer J Clin (2013) 63(1):11-30. doi:10.3322/caac.21166

2. Cecil TD, Sexton R, Moran BJ, Heald RJ. Total mesorectal excision results in low local recurrence rates in lymph node-positive rectal cancer. Dis Colon Rectum (2004) 47(7):1145-9. doi:10.1007/s10350-004-0086-6 discussion 1149-50

3. Kapiteijn E, Marijnen CA, Nagtegaal ID, Putter H, Steup WH, Wiggers T, et al. Preoperative radiotherapy combined with total mesorectal excision for resectable rectal cancer. N Engl J Med (2001) 345(9):638-46. doi:10.1056/ NEJMoa010580

4. Kaminsky-Forrett MC, Conroy T, Luporsi E, Peiffert D, Lapeyre M, Boissel P, et al. Prognostic implications of downstaging following preoperative radiation therapy for operable T3-T4 rectal cancer. Int J Radiat Oncol Biol Phys (1998) 42(5):935-41. doi:10.1016/S0360-3016(98)00345-9

5. Fisher B, Wolmark N, Rockette H, Redmond C, Deutsch M, Wickerham DL, et al. Postoperative adjuvant chemotherapy or radiation therapy for rectal cancer: results from NSABP protocol R-01. J Natl Cancer Inst (1988) 80(1):21-9. doi:10.1093/jnci/80.1.21

6. Krook JE, Moertel CG, Gunderson LL, Wieand HS, Collins RT, Beart RW, et al. Effective surgical adjuvant therapy for high-risk rectal carcinoma. N Engl J Med (1991) 324(11):709-15. doi:10.1056/NEJM199103143241101

7. Krishnamurthi SS, Seo Y, Kinsella TJ. Adjuvant therapy for rectal cancer. Clin Colon Rectal Surg (2007) 20(3):167-81. doi:10.1055/s-2007-984861

8. Adell G, Sun XF, Stal O, Klintenberg C, Sjodahl R, Nordenskjold B. p53 Status: an indicator for the effect of preoperative radiotherapy of rectal cancer. Radiother Oncol (1999) 51(2):169-74. doi:10.1016/S0167-8140(99)00041-9

9. Berger C, de Muret A, Garaud P, Chapet S, Bourlier P, Reynaud-Bougnoux A, et al. Preoperative radiotherapy (RT) for rectal cancer: predictive factors of tumor downstaging and residual tumor cell density (RTCD): prognostic implications. Int J Radiat Oncol Biol Phys (1997) 37(3):619-27. doi:10.1016/S03603016(96)00577-9

10. Dahlberg M, Glimelius B, Graf W, Pahlman L. Preoperative irradiation affects functional results after surgery for rectal cancer: results from a randomized study. Dis Colon Rectum (1998) 41(5):543-9. doi:10.1007/BF02235256 discussion 549-51

11. Francois Y, Nemoz CJ, Baulieux J, Vignal J, Grandjean JP, Partensky C, et al. Influence of the interval between preoperative radiation therapy and surgery on downstaging and on the rate of sphincter-sparing surgery for rectal cancer: the Lyon R90-01 randomized trial. J Clin Oncol (1999) 17(8):2396.

12. Glimelius B, Isacsson U, Jung B, Pahlman L. Radiotherapy in addition to radical surgery in rectal cancer: evidence for a dose-response effect favoring preoperative treatment. Int J Radiat Oncol Biol Phys (1997) 37(2):281-7. doi:10.1016/S0360-3016(96)00510-X

13. Minsky BD, Cohen AM, Kemeny N, Enker WE, Kelsen DP, Reichman B, et al. Enhancement of radiation-induced downstaging of rectal cancer by fluorouracil and high-dose leucovorin chemotherapy. J Clin Oncol (1992) 10(1):79-84.

14. Sauer R, Becker H, Hohenberger W, Rödel C, Wittekind C, Fietkau R, et al. Preoperative versus postoperative chemoradiotherapy for rectal cancer. $N$ Engl J Med (2004) 351(17):1731-40. doi:10.1056/NEJMoa040694

15. Camma C, Giunta M, Fiorica F, Pagliaro L, Craxi A, Cottone M. Preoperative radiotherapy for resectable rectal cancer: a meta-analysis. JAMA (2000) 284(8):1008-15. doi:10.1001/jama.284.8.1008

16. Crane CH, Skibber JM, Birnbaum EH, Feig BW, Singh AK, Delclos ME, et al. The addition of continuous infusion 5-FU to preoperative radiation therapy increases tumor response, leading to increased sphincter preservation in locally advanced rectal cancer. Int J Radiat Oncol Biol Phys (2003) 57(1):84-9. doi:10.1016/S0360-3016(03)00532-7

17. Minsky BD, Cohen AM, Enker WE, Saltz L, Guillem JG, Paty PB, et al. Preoperative 5-FU, low-dose leucovorin, and radiation therapy for locally advanced and unresectable rectal cancer. Int J Radiat Oncol Biol Phys (1997) 37(2):289-95. doi:10.1016/S0360-3016(96)00487-7

18. Bouzourene H, Bosman FT, Seelentag W, Matter M, Coucke P. Importance of tumor regression assessment in predicting the outcome in patients with locally 
advanced rectal carcinoma who are treated with preoperative radiotherapy. Cancer (2002) 94(4):1121-30. doi:10.1002/cncr.10327.abs

19. Maas M, Nelemans PJ, Valentini V, Das P, Rödel C, Kuo LJ, et al. Long-term outcome in patients with a pathological complete response after chemoradiation for rectal cancer: a pooled analysis of individual patient data. Lancet Oncol (2010) 11(9):835-44. doi:10.1016/S1470-2045(10)70172-8

20. Martin ST, Heneghan HM, Winter DC. Systematic review and meta-analysis of outcomes following pathological complete response to neoadjuvant chemoradiotherapy for rectal cancer. Br JSurg (2012) 99(7):918-28. doi:10.1002/bjs.8702

21. Park IJ, You YN, Agarwal A, Skibber JM, Rodriguez-Bigas MA, Eng C, et al. Neoadjuvant treatment response as an early response indicator for patients with rectal cancer. J Clin Oncol (2012) 30(15):1770-6. doi:10.1200/JCO.2011.39.7901

22. Cubillo A, Hernando-Requejo O, García-García E, Rodriguez-Pascual J, de Vicente E, Morelli P, et al. A prospective pilot study of target-guided personalized chemotherapy with intensity-modulated radiotherapy in patients with early rectal cancer. Am J Clin Oncol (2012). doi:10.1097/COC.0b013e31826e0703

23. Garcia-Aguilar J, Hernandez de Anda E, Sirivongs P, Lee SH, Madoff RD, Rothenberger DA. A pathologic complete response to preoperative chemoradiation is associated with lower local recurrence and improved survival in rectal cancer patients treated by mesorectal excision. Dis Colon Rectum (2003) 46(3):298-304. doi:10.1007/s10350-004-6545-x

24. Janjan NA, Abbruzzese J, Pazdur R, Khoo VS, Cleary K, Dubrow R, et al. Prognostic implications of response to preoperative infusional chemoradiation in locally advanced rectal cancer. Radiother Oncol (1999) 51(2):153-60. doi:10.1016/S0167-8140(99)00054-7

25. Onaitis MW, Noone RB, Hartwig M, Hurwitz H, Morse M, Jowell P, et al. Neoadjuvant chemoradiation for rectal cancer: analysis of clinical outcomes from a 13-year institutional experience. Ann Surg (2001) 233(6):778-85. doi:10.1097/00000658-200106000-00007

26. Read TE, McNevin MS, Gross EK, Whiteford HM, Lewis JL, Ratkin G, et al. Neoadjuvant therapy for adenocarcinoma of the rectum: tumor response and acute toxicity. Dis Colon Rectum (2001) 44(4):513-22. doi:10.1007/BF02234323

27. Kalady MF, de Campos-Lobato LF, Stocchi L, Geisler DP, Dietz D, Lavery IC, et al. Predictive factors of pathologic complete response after neoadjuvant chemoradiation for rectal cancer. Ann Surg (2009) 250(4):582-9. doi:10.1097/ SLA.0b013e3181b91e63

28. Holm T, Singnomklao T, Rutqvist LE, Cedermark B. Adjuvant preoperative radiotherapy in patients with rectal carcinoma. Adverse effects during long term follow-up of two randomized trials. Cancer (1996) 78(5):968-76. doi:10.1002/(SICI) 1097-0142(19960901)78:5<968::AID-CNCR5>3.3.CO;2-2

29. Habr-Gama A. Assessment and management of the complete clinical response of rectal cancer to chemoradiotherapy. Colorectal Dis (2006) 8(Suppl 3):21-4. doi:10.1111/j.1463-1318.2006.01066.x

30. Maas M, Beets-Tan RG, Lambregts DM, Lammering G, Nelemans PJ, Engelen $\mathrm{SM}$, et al. Wait-and-see policy for clinical complete responders after chemoradiation for rectal cancer. J Clin Oncol (2011) 29(35):4633-40. doi:10.1200/JCO. 2011.37.7176

31. Smith JD, Ruby JA, Goodman KA, Saltz LB, Guillem JG, Weiser MR, et al. Nonoperative management of rectal cancer with complete clinical response after neoadjuvant therapy. Ann Surg (2012) 256(6):965-72. doi:10.1097/SLA. 0b013e3182759f1c

32. Kuremsky JG, Tepper JE, McLeod HL. Biomarkers for response to neoadjuvant chemoradiation for rectal cancer. Int J Radiat Oncol Biol Phys (2009) 74(3):673-88. doi:10.1016/j.ijrobp.2009.03.003

33. Zeestraten EC, Kuppen PJ, van de Velde CJ, Marijnen CA. Prediction in rectal cancer. Semin Radiat Oncol (2012) 22(2):175-83. doi:10.1016/j.semradonc. 2011.12.005

34. Cascinu S, Catalano V, Aschele C, Barni S, Debernardis D, Gallo L, et al. Immunohistochemical determination of $\mathrm{p} 53$ protein does not predict clinical response in advanced colorectal cancer with low thymidylate synthase expression receiving a bolus 5-fluorouracil-leucovorin combination. Ann Oncol (2000) 11(8):1053-6. doi:10.1023/A:1008393010472

35. Tannapfel A, Nusslein S, Fietkau R, Katalinic A, Kockerling F, Wittekind C. Apoptosis, proliferation, bax, bcl-2 and p53 status prior to and after preoperative radiochemotherapy for locally advanced rectal cancer. Int J Radiat Oncol Biol Phys (1998) 41(3):585-91. doi:10.1016/S0360-3016(98)00076-5

36. Edler D, Hallstrom M, Johnston PG, Magnusson I, Ragnhammar P, Blomgren $\mathrm{H}$. Thymidylate synthase expression: an independent prognostic factor for local recurrence, distant metastasis, disease-free and overall survival in rectal cancer. Clin Cancer Res (2000) 6(4):1378-84.

37. Johnston PG, Fisher ER, Rockette HE, Fisher B, Wolmark N, Drake JC, et al. The role of thymidylate synthase expression in prognosis and outcome of adjuvant chemotherapy in patients with rectal cancer. J Clin Oncol (1994) 12(12):2640-7.

38. Leichman CG, Lenz HJ, Leichman L, Danenberg K, Baranda J, Groshen S, et al. Quantitation of intratumoral thymidylate synthase expression predicts for disseminated colorectal cancer response and resistance to protracted-infusion fluorouracil and weekly leucovorin. J Clin Oncol (1997) 15(10):3223-9.

39. Lenz HJ, Leichman CG, Danenberg KD, Danenberg PV, Groshen S, Cohen H, et al. Thymidylate synthase mRNA level in adenocarcinoma of the stomach: a predictor for primary tumor response and overall survival. J Clin Oncol (1996) 14(1):176-82.

40. Lenz HJ, Danenberg KD, Leichman CG, Florentine B, Johnston PG, Groshen S, et al. p53 and thymidylate synthase expression in untreated stage II colon cancer: associations with recurrence, survival, and site. Clin Cancer Res (1998) 4(5):1227-34.

41. Salonga D, Danenberg KD, Johnson M, Metzger R, Groshen S, Tsao-Wei DD, et al. Colorectal tumors responding to 5 -fluorouracil have low gene expression levels of dihydropyrimidine dehydrogenase, thymidylate synthase, and thymidine phosphorylase. Clin Cancer Res (2000) 6(4):1322-7.

42. Tan BR, Thomas F, Myerson RJ, Zehnbauer B, Trinkaus K, Malyapa RS, et al. Thymidylate synthase genotype-directed neoadjuvant chemoradiation for patients with rectal adenocarcinoma. J Clin Oncol (2011) 29(7):875-83. doi:10.1200/JCO.2010.32.3212

43. Kelley RK, Venook AP. Prognostic and predictive markers in stage II colon cancer: is there a role for gene expression profiling? Clin Colorectal Cancer (2011) 10(2):73-80. doi:10.1016/j.clcc.2011.03.001

44. Kihara C, Tsunoda T, Tanaka T, Yamana H, Furukawa Y, Ono K, et al. Prediction of sensitivity of esophageal tumors to adjuvant chemotherapy by cDNA microarray analysis of gene-expression profiles. Cancer Res (2001) 61(17):6474-9.

45. Schauer M, Janssen KP, Rimkus C, Raggi M, Feith M, Friess H, et al. Microarraybased response prediction in esophageal adenocarcinoma. Clin Cancer Res (2010) 16(1):330-7. doi:10.1158/1078-0432.CCR-09-1673

46. Venook AP, Niedzwiecki D, Lopatin M, Ye X, Lee M, Friedman PN, et al. Biologic determinants of tumor recurrence in stage II colon cancer: validation study of the 12-gene recurrence score in cancer and leukemia group B (CALGB) 9581. J Clin Oncol (2013) 31(14):1775-81. doi:10.1200/JCO.2012.45.1096

47. Della Vittoria Scarpati G, Falcetta F, Carlomagno C, Ubezio P, Marchini S, de Stefano A, et al. A specific miRNA signature correlates with complete pathological response to neoadjuvant chemoradiotherapy in locally advanced rectal cancer. Int J Radiat Oncol Biol Phys (2012) 83(4):1113-9. doi:10.1016/j.ijrobp. 2011.09.030

48. Rodel C, Martus P, Papadoupolos T, Füzesi L, Klimpfinger M, Fietkau $\mathrm{R}$, et al. Prognostic significance of tumor regression after preoperative chemoradiotherapy for rectal cancer. J Clin Oncol (2005) 23(34):8688-96. doi:10.1200/JCO.2005.02.1329

49. Shi L, Campbell G, Jones WD, Campagne F, Wen Z, Walker SJ, et al. The MicroArray Quality Control (MAQC)-II study of common practices for the development and validation of microarray-based predictive models. Nat Biotechnol (2010) 28(8):827-38. doi:10.1038/nbt.1665

50. Guilherme A, Soriano NA, Bose S, Holik J, Bose A, Pomerleau DP, et al. EHD2 and the novel $\mathrm{EH}$ domain binding protein EHBP1 couple endocytosis to the actin cytoskeleton. J Biol Chem (2004) 279(11):10593-605. doi:10.1074/jbc. M307702200

51. Gudmundsson J, Sulem P, Rafnar T, Bergthorsson JT, Manolescu A, Gudbjartsson D, et al. Common sequence variants on 2 p15 and Xp11.22 confer susceptibility to prostate cancer. Nat Genet (2008) 40(3):281-3. doi:10.1038/ng.89

52. Kim HS, Lee MS. STAT1 as a key modulator of cell death. Cell Signal (2007) 19(3):454-65. doi:10.1016/j.cellsig.2006.09.003

53. Aaronson DS, Horvath CM. A road map for those who don't know JAK-STAT. Science (2002) 296(5573):1653-5. doi:10.1126/science.1071545

54. Gordziel C, Bratsch J, Moriggl R, Knosel T, Friedrich K. Both STAT1 and STAT3 are favourable prognostic determinants in colorectal carcinoma. Br J Cancer (2013) 109(1):138-46. doi:10.1038/bjc.2013.274

55. Simpson JA, Al-Attar A, Watson NF, Scholefield JH, Ilyas M, Durrant LG. Intratumoral T cell infiltration, MHC class I and STAT 1 as biomarkers of good prognosis in colorectal cancer. Gut (2010) 59(7):926-33. doi:10.1136/gut.2009.194472 
56. Tarze A, Deniaud A, Le Bras M, Maillier E, Molle D, Larochette N, et al. GAPDH, a novel regulator of the pro-apoptotic mitochondrial membrane permeabilization. Oncogene (2007) 26(18):2606-20. doi:10.1038/sj.onc.1210074

57. Tang Z, Yuan S, Hu Y, Zhang H, Wu W, Zeng Z, et al. Over-expression of GAPDH in human colorectal carcinoma as a preferred target of 3-bromopyruvate propyl ester. J Bioenerg Biomembr (2012) 44(1):117-25. doi:10.1007/s10863012-9420-9

58. Mani A, Gelmann EP. The ubiquitin-proteasome pathway and its role in cancer. J Clin Oncol (2005) 23(21):4776-89. doi:10.1200/JCO.2005.05.081

59. Voutsadakis IA. The ubiquitin-proteasome system in colorectal cancer. Biochim Biophys Acta (2008) 1782(12):800-8. doi:10.1016/j.bbadis.2008.06.007

Conflict of Interest Statement: The authors declare that the research was conducted in the absence of any commercial or financial relationships that could be construed as a potential conflict of interest.
Received: 28 August 2013; accepted: 11 November 2013; published online: 25 November 2013.

Citation: Chan J, Kinsella MT, Willis JE, Hu H, Reynolds H Jr, Delaney C, McCulla A, Deharo S, Ahdesmäki M, Allen WL, Johnston PG and Kinsella TJ (2013) A predictive genetic signature for response to fluoropyrimidine-based neoadjuvant chemoradiation in clinical Stage II and III rectal cancer. Front. Oncol. 3:288. doi: 10.3389/fonc. 2013.00288

This article was submitted to Radiation Oncology, a section of the journal Frontiers in Oncology.

Copyright (c) 2013 Chan, Kinsella, Willis, Hu, Reynolds Jr, Delaney, McCulla, Deharo, Ahdesmäki, Allen, Johnston and Kinsella. This is an open-access article distributed under the terms of the Creative Commons Attribution License (CC BY). The use, distribution or reproduction in other forums is permitted, provided the original author(s) or licensor are credited and that the original publication in this journal is cited, in accordance with accepted academic practice. No use, distribution or reproduction is permitted which does not comply with these terms. 